\title{
Reminiscing Crashing Waves and Romanticism in Zhao Xiaosheng's Fisherman Song
}

Xue Ke, Cultural Centre, University of Malaya, Kuala Lumpur, Malaysia; College of Humanities, Qinzhou University, China.

shengguandanzi@163.com

and

Loo Fung Ying, Cultural Centre, University of Malaya, Kuala Lumpur, Malaysia loofy@um.edu.my

(C) 2017 University of Malaya. All rights reserved.

Malaysian Journal of Performing and Visual Arts, Volume 3, 2017

\begin{abstract}
Fisherman Song or Yuge (1975) is one of Zhao Xiaosheng's solo piano compositions that was composed during Cultural Revolution in China. It expresses the composer's experience after following the fishermen taking their vessels to the sea, including his realization of the insignificance of humans against nature. Based on the analysis of the structure, tonality, harmony, melody and tempo, the compositional character that combines elements of the West and East is presented by virtue of neo-romantic aesthetic, composing techniques, and application of pentatonic elements and Chinese work song. Score analysis and an interview with the composer provided details on the understandings of Fisherman Song as a new solo piano work during the period of Cultural Revolution.
\end{abstract}

Keywords: Fisherman Song, Zhao Xiaosheng, Piano, Analysis, Performance practice

\section{Introduction}

Fisherman Song or Yuge (渔歌) was composed by Zhao Xiaosheng (赵晓生) (1945- ) in 1975 and was first published by Shanghai People's Publishing House in 1977 under the new title of Yangfanpolang Yuge Liang (扬帆破浪渔歌亮, Fishing Song to Celebrate the Conquest of Storm in the Sea) to replace its original name due to political concerns. In addition, this was due to a coincidental conflict with another musical composition by Yu Huiyong (于会泳) of the same title for the requirement of the socialist political propaganda. It was only in 2015, the original title Fisherman Song was used in the second edition.

The Chinese Cultural Revolution was launched in 1966 by Mao Zedong as a quest to sustain Socialism and Marxism (Robinson, 1968), which ended with his death in 1976. During the 10 years of revolutionary movement, music was required to conform to the political rhetoric (Pang, Clark, \& Tsai, 2016). In addition, Western music such as 
compositions by Beethoven, Chopin, and Schubert were condemned as bourgeois poison and thus prohibited (Mittler, 2003). Accordingly, the yangbanxi (样板戏), or model opera, as a mainstream culture, was actively staged and completely reflected the surging class struggle. Meanwhile, the eulogy of socialism and collection of folk music became the cores of music activities when intellectuals were forced to engage in physical labor, to ingratiate Mao Zedong's directive that intellectuals should interact with laborers and participate in their activities so that their artistic work is directly influenced from labor practices (Liang, 1996). Zhao was assigned to work in the fishing ground that was located at Hengsha island beside Shanghai and it was his experience in the rough sea that inspired him to write Fisherman Song. During an interview at the composer's home in Shanghai on November 4, 2016. Zhao depicts the hardship of living in the sea:

In 1975, I was forced to fishing labour, it was true that I fished on the sea, not a trick, the fishing vessel was only 37 ton, do you know what is the meaning of 37 ton vessel in the sea? Do you know the weight of modern vessel? I tell you, the vessel Zhenghe utilized to voyage was more than 3700 ton, it was over 100 times than mine...so what does it mean when a 37 -ton vessel float on the sea. The waves that we encountered was two times higher than this room [the composer's study room], about 3 or 4 meters, the vessel was rushed up by the waves, vertically... and fell down all of a sudden, that was the structure of boat and when it descended, it made you vomit... I was not the only one who vomited, everyone vomited, including fishermen... the fishes were alive, you can never see a living ribbonfish, I saw, ribbonfish was alive as it leave the sea but within 20 seconds, it died... Sea eel, you know? Living sea eel, with sharp teeth? They hit the sea eel with a wooden hammer that was captured in the net. Bang, it fainted, or died. Or if it bites you, your arm would fracture. So don't you think it is fun in the sea. (translation by authors)

Extreme sea sickness and constant spewing of vomit and blood were Zhao's experience of the vulnerability of human working in the sea on a tiny fishing vessel. Inspired by the bravery of fishermen, Zhao composed Fisherman Song to describe the fisherman's way of life and sentiments when bravery becomes a test to nature's call of atrocious weather.

Liang (1996) described the piece as a rare and original piano composition during Cultural Revolution because most piano works of the time were transcriptions. Fisherman Song was neglected by most scholars even those who wrote about the composer Zhao such as Li Tiantian (2014). An earlier study by Kong Wenwen (2009) mentioned Fisherman Song by introducing the piece's simple background, musical form and harmony. However, there has yet to be a detailed study on the piece that has much cultural and aesthetical concern. Therefore, this paper attempts to provide a detailed analysis of the work with an interview with the composer for a deeper insight into its music and performance practice.

\section{Synthesis of Western and Chinese Music Forms}

Fisherman Song reflects Zhao's experience of hardship at the sea and his relationship 
working with fishermen. During his interview, the composer described:

I stayed on the sea for ten days, then composed this work. Therefore, you can see the waves in this repertoire, it's descriptive, not just description, an experience. About singing Fisherman Song, the tone of Fisherman Song is created by myself, not transcription... This is created by myself, I state beforehand. (translation by authors) (X.S. Zhao, personal interview, November 4, 2017)

By analyzing the score of Fisherman Song based on the Western theory, it is obvious that this solo work is formed as compound ternary. However, during the interview, Zhao (personal interview, November 4, 2017) further suggests that this composition also can be viewed as a symmetry arch shape that is called yanzhanti (衍展体, extensibility), which presents a continuous process of development as a common musical structure in Chinese music. Table 1 shows the detailed segments of both the Western and Chinese forms.

Table 1

The Segments of Both Western and Chinese Forms

\begin{tabular}{|c|c|c|c|c|c|}
\hline Compound ternary & $\begin{array}{c}\text { Introductio } \\
\mathrm{n}\end{array}$ & $\mathrm{A}$ & $\mathrm{B}$ & $\mathrm{A}^{1}$ & Coda \\
\hline Yanzhanti & $\mathrm{A}$ & $\mathrm{B}$ & $\mathrm{C}$ & $\mathrm{B}^{1}$ & $\mathrm{~A}^{1}$ \\
\hline Measure number & $1-16$ & $17-50$ & $51-189$ & $\begin{array}{c}190-20 \\
5\end{array}$ & $\begin{array}{c}206-23 \\
0\end{array}$ \\
\hline
\end{tabular}

On the surface, the segments of two forms are similar except for different appellations. However, the compound ternary form emphasizes the contrast between first section (A) and second section (B), while the movement replaces contrast in yanzhanti, which is a distinct character of Chinese music to Western.

Listening to Zhao's performance and analyzing the score of Fisherman Song, the introduction is more likely to an isolated section due to its specific depiction and strongly melodious expression. As X.S. Zhao (personal interview, November 4, 2017) stressed, the wave is described in this composition accordingly; the beginning of music (see Figure 1) signifies the scene of waves crashing in the sea with thirty-second-note arpeggios, among which some notes added the sostenuto "-" to outline the melodies that are hidden in the arpeggios that seem to depict the splashing waters. The music from mm. 6 onwards, have four paralleled phrases accompanied by the rhythm pattern of sextuplet with sixteenth notes. Every phrase nearly contains three bars except for first phrase while another three phrases are developments and expansions on the basis of first phrase. Therefore, authors prefer to view this portion as the section A of yanzhanti rather than the introduction of compound ternary. 

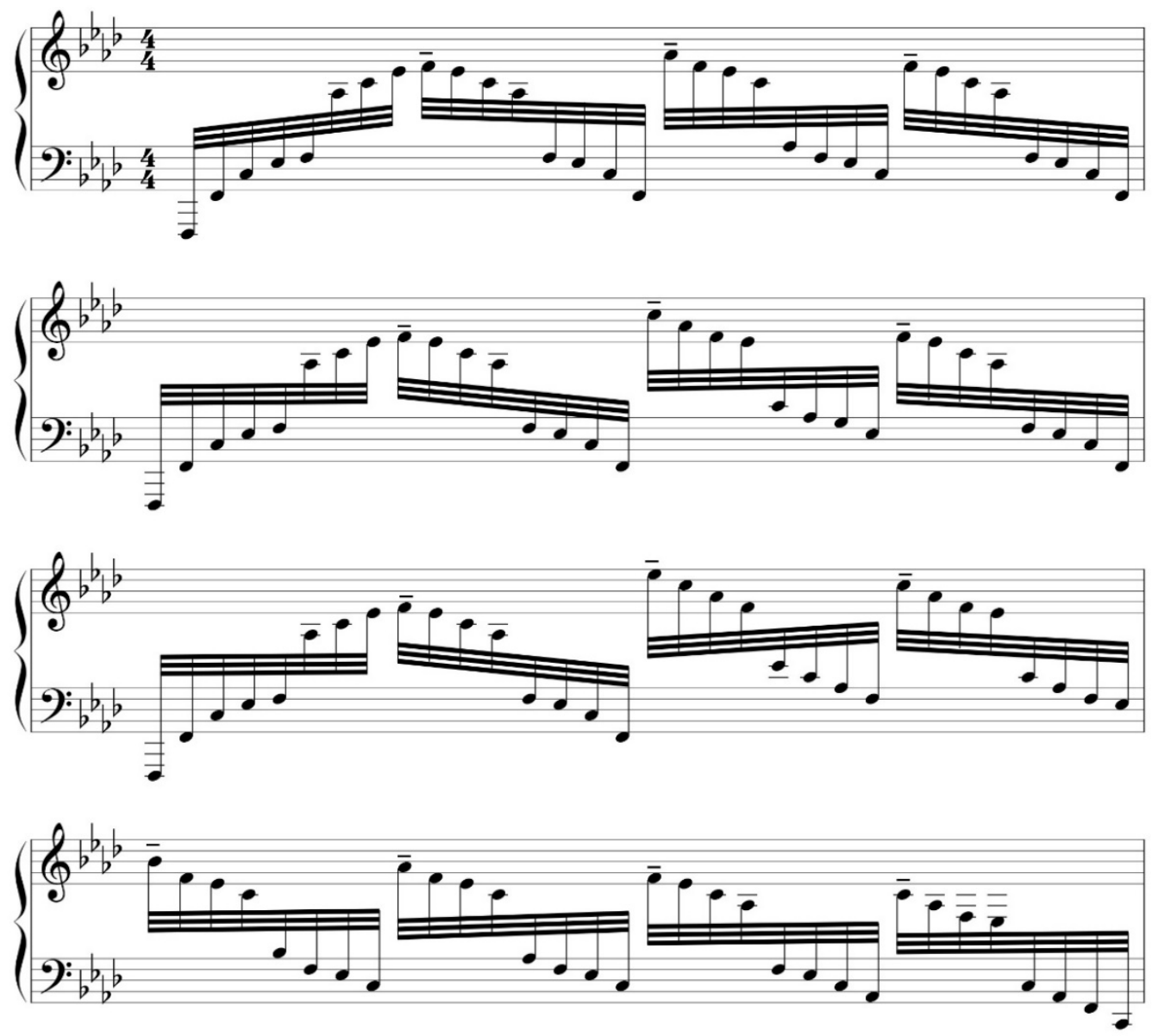

Figure 1. The description of waves crashing in the sea, mm.1-4. Extract (C) 2015 Shanghai Century Publishing (Group) Co., Ltd. Shanghai. Reproduced with permission.

Apart from Western compound ternary form as entire musical form, another Western form variation is employed in the first part (A) from $\mathrm{mm}$. 17. The theme and two-time variations reflect Zhao's skilled writing. This variation is compound due to the formation of two themes: one is in high voice (a) (see Figure 2a), and the other is in bass voice (b) (see Figure 2b), with both their tones and keys being completely distinct. The melodious phrases of the first theme imitates the common songs sung by fishermen at the sea repeats twice with two octaves apart, followed by a new melody played by the left hand in the bass voice; the second theme acts as a male voice corresponding the female voice of the first theme. In the first variation, the variated first theme changes from single notes to octaves and merely appears once, followed by the second part that is one octave higher than the original. The second variation reserves the melodic mode of octaves, while the accompaniment utilizes the sextuplet patterns of the introductory section. The major transformation of the second theme in the second variation show the aspects of replacement of phrases by repeated motives 
and the key returning to $\mathrm{Ab}$ Gong scale (Ab宫调). As a sequence, it applies the tail of the first theme as ending (see Table 2).

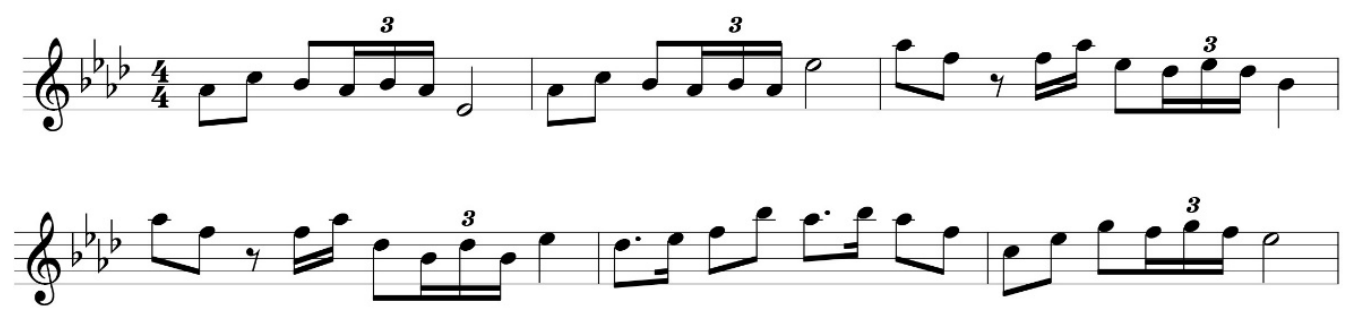

Figure 2a. The first theme in high voice, mm.17-22. Extract (C) 2015 Shanghai Century Publishing (Group) Co., Ltd. Shanghai. Reproduced with permission.

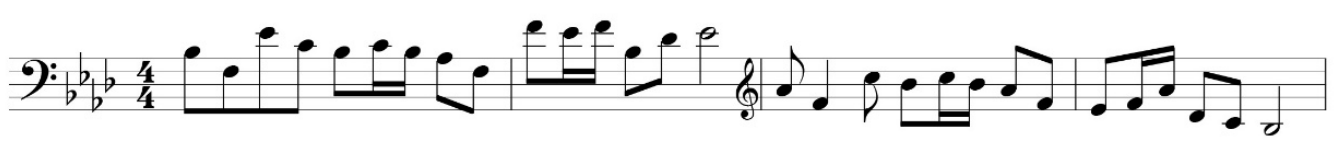

Figure 2b. The second theme in low voice, mm.17-22. Extract (C) 2015 Shanghai Century Publishing (Group) Co., Ltd. Shanghai. Reproduced with permission.

Table 2

Structure of First Part

\begin{tabular}{|c|c|c|c|c|c|c|}
\hline Part & \multicolumn{5}{|c|}{ A } \\
\hline Section & \multicolumn{2}{|c|}{ Theme (A) } & \multicolumn{2}{|c|}{ Variation 1 (A $\left.{ }^{1}\right)$} & \multicolumn{2}{|c|}{ Variation 2 $\left(\mathrm{A}^{2}\right)$} \\
\hline Phrase & $a$ & $b$ & $a^{1}$ & $b^{1}$ & $a^{2}$ & $b^{2}$ \\
\hline $\begin{array}{c}\text { Measure } \\
\text { number }\end{array}$ & $17-29$ & $30-33$ & $34-37$ & $38-41$ & $42-45$ & $46-50$ \\
\hline Key & $\begin{array}{c}\mathrm{Ab} \\
\text { Gong } \\
\text { scale }\end{array}$ & $\begin{array}{c}\text { Shang } \\
\text { scale }\end{array}$ & $\begin{array}{c}\text { Ab Gong } \\
\text { scale }\end{array}$ & $\begin{array}{c}\mathrm{Ab} \\
\text { Shang } \\
\text { scale }\end{array}$ & $\begin{array}{c}\text { Ab Gong } \\
\text { scale }\end{array}$ & $\begin{array}{c}\mathrm{Ab} \\
\text { Gong } \\
\text { scale }\end{array}$ \\
\hline
\end{tabular}

Similar to the form of part A, the two variations constitute the part B (see Table 3), which also contains theme and two-time variations. 
Table 3

Structure of Second Part

\begin{tabular}{|c|c|c|c|c|c|c|c|c|}
\hline Part & \multicolumn{8}{|c|}{ B } \\
\hline Section & \multirow{2}{*}{$\begin{array}{c}\text { Transi } \\
\text { tion }\end{array}$} & \multicolumn{3}{|c|}{ B } & \multirow{2}{*}{$\begin{array}{c}\text { Connectio } \\
\mathbf{n}\end{array}$} & \multicolumn{3}{|c|}{$\mathbf{B}^{1}$} \\
\hline Phrase & & $c$ & $c^{l}$ & $c^{2}$ & & $d$ & $d^{l}$ & $d^{2}$ \\
\hline $\begin{array}{c}\text { Measur } \\
\text { e } \\
\text { number }\end{array}$ & $51-52$ & $53-76$ & $\begin{array}{c}77-9 \\
2\end{array}$ & $\begin{array}{c}93-12 \\
4\end{array}$ & $125-140$ & $\begin{array}{c}141-1 \\
48\end{array}$ & $\begin{array}{l}149 \\
156\end{array}$ & $\begin{array}{c}157-18 \\
9\end{array}$ \\
\hline Key & & $\begin{array}{c}\mathrm{Ab} \\
\text { Shang } \\
\text { scale }\end{array}$ & $\begin{array}{c}\mathrm{Ab} \\
Y u \\
\mathrm{scal} \\
\mathrm{e}\end{array}$ & $\begin{array}{c}\mathrm{Ab} \mathrm{Yu} \\
\text { scale }\end{array}$ & & $\begin{array}{c}\mathrm{Eb} \\
\text { Gong } \\
\text { scale }\end{array}$ & $\begin{array}{c}\text { F Yu } \\
\text { scal } \\
\text { e }\end{array}$ & $\begin{array}{c}\mathrm{Db} \\
\text { Shang } \\
\text { scale }\end{array}$ \\
\hline
\end{tabular}

The synthesis of the Western and Chinese structures are not only reflected in musical forms, but also in the inner constitution covered in the Western ternary form, such as the phrase consists of $q i$ (起, starting), cheng (承, undertaking), zhuan (转, turning), and he (合, ending) in section B that is covered by the variation form.

The inspiration of qi, cheng, zhuan and he was initially from Chinese ancient verse of Liu Xizai, a scholar in the Qing dynasty, as follows:

起、承、转、合四字, 起者, 起下也, 连合亦起在内; 合者, 合 上也，连起也合在内，中间用承用转，皆兼顾起合也 (Liu, 1978)。

Regarding the implication of four Chinese characters of qi, cheng, zhuan, and he, within qi (beginning) there is he (closing) where he is a respond to the beginning of text. Within he it also consists of $q i$, where the coherence of cheng and zhuan are the content of the text, in this way, it presents a text of completion. (translation by author)

Huang (2010) explained that qi, cheng, zhuan, and he is an abstractive structure of time, space, and others, which gradually becomes a way of logical thinking and an unconscious psychological structure of Chinese tradition, as it was used to be perceived continuously. The structure of qi, cheng, zhuan and he not only applies in literature, but plays an irreplaceable role in Chinese music, in which the music is expressed by the musical descriptions such as tension, relaxation, stability, instability, complexity, simplicity, definitude, purity, descending and ascending (Kang, 2009).

A typical application shows the characters of qi, cheng, zhuan and he in phrase $c$ 
composed by the theme of section B. X.S. Zhao (personal interview, November 4, 2017) explained that the idea of the first passage (mm. 53-56) was taken from his memory of lawang haozi (拉网号子, pulling fishing net) ${ }^{1}$. As cheng (mm.59-62) means continuous development, it maintains the melodic mode and rhythm pattern except for the tonality changes changed from $A b$ Shang scale to $D b$ Shang scale. The passage of zhuan (mm. 65-68) reserves the tonality of cheng while the melody mode and rhythm pattern alters to create an effect of conversion in musical mood. The function of he is to allow the tonality, rhythm pattern, and melodic mode return back to the features in the first passage (see Figure 3).

Qi

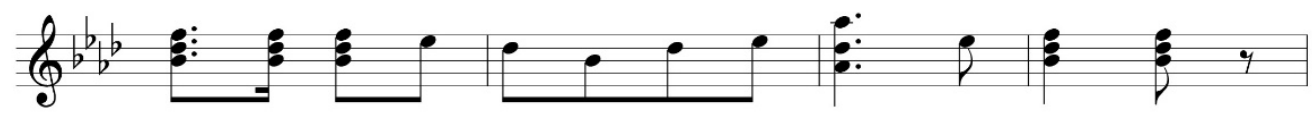

Cheng

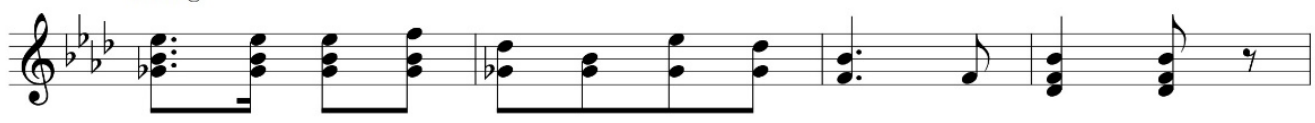

Zhuan

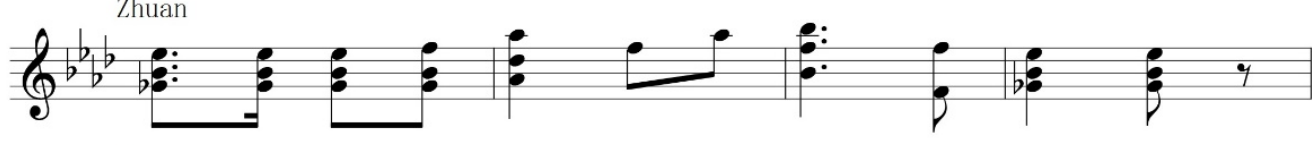

He

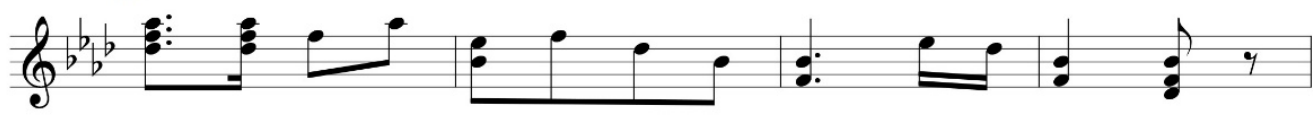

Figure 3. The character of qi, cheng, zhuan, and he in phrase c: qi, mm.53-56; cheng, mm.59-62; zhuan, mm.65-78; he, mm.71-74. Extract (C) 2015 Shanghai Century Publishing (Group) Co., Ltd. Shanghai. Reproduced with permission.

Due to the mode to chant the ancient poem by virtue of singing, the structure of $q i$, cheng, zhuan, and he became a common form in Chinese folk song (Fan, 2015) as well as reflects the musical custom of Han (Jiang, 1999).The application of this structure in Fisherman Song reverts the manner of lawang haozi vividly and shows Zhao's thinking mode of composition that roots in Chinese culture, by which the melodies he composed therefore coincide with Chinese taste, or aesthetics. Meanwhile, the Western theory that covers the entire composition as a main approach more or less reflects the central status of Western music in China at that time.

Lawang haozi is variated two times in the following context based on the rhythmic transformation from dynamic rhythm with dots, through the rhythm pattern of duplet, to that of the triplet. In the first variation (mm. 77-92) (see Figure 4), the melody changes from a high register to low register and the chords consist of motive in the first phrase that are replaced by repeated intervals. Although the melody returns to a high register in the second variation (mm. 93-124) (see Figure 5), it is outlined by octaves instead. 

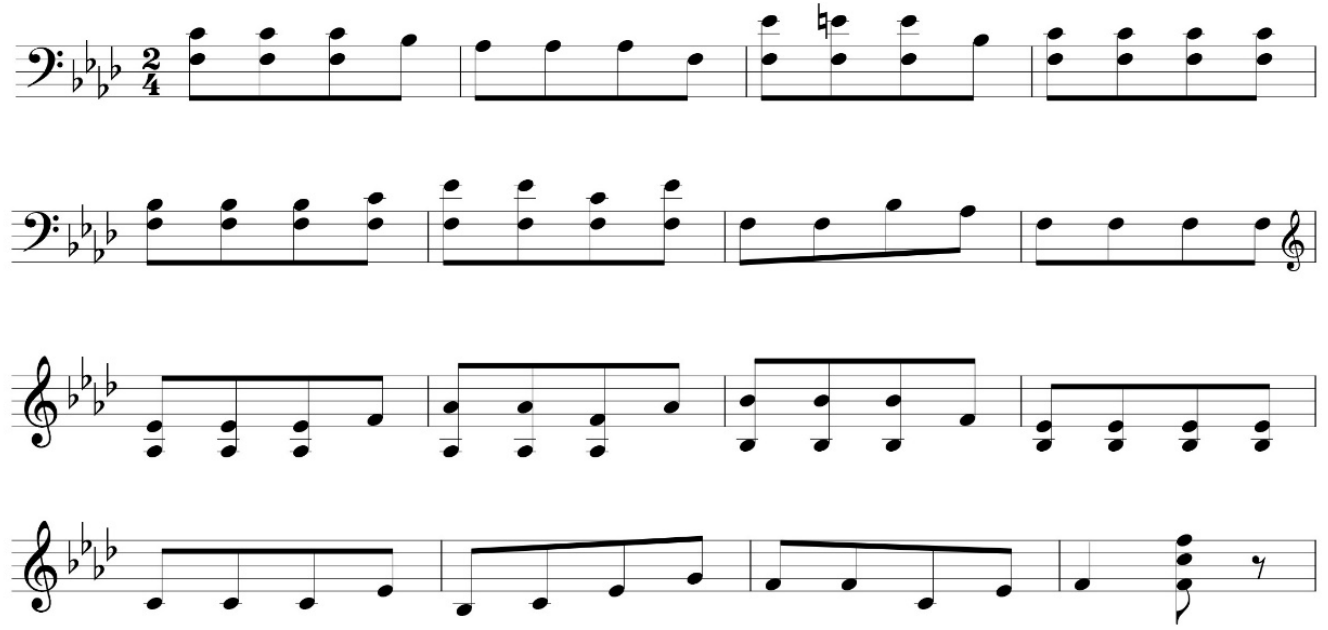

Figure 4. The melodies of first variation, mm. 77-92. Extract (C) 2015 Shanghai Century Publishing (Group) Co., Ltd. Shanghai. Reproduced with permission.
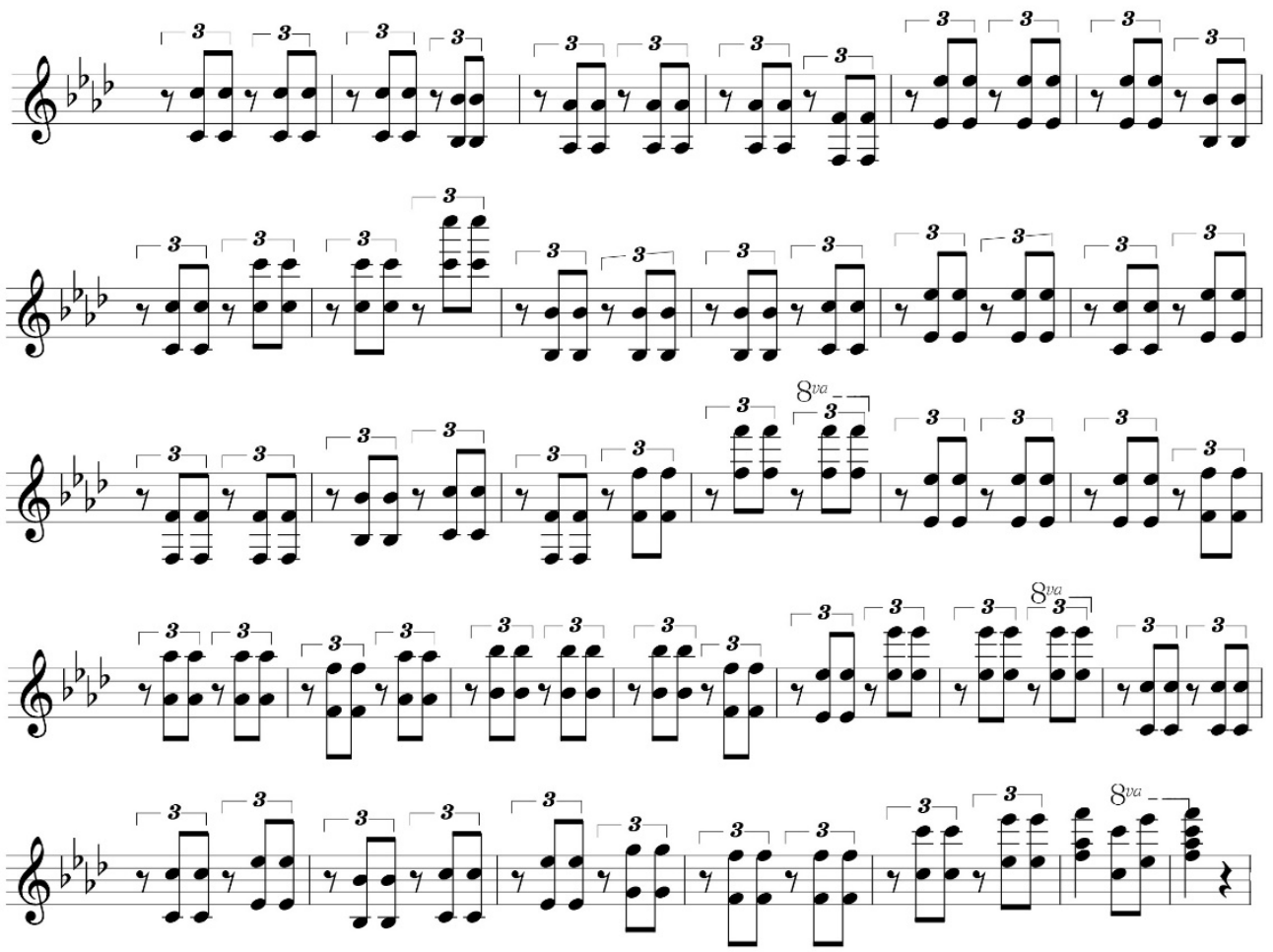

Figure 5. The melodies of second variation, mm. 93-124. Extract (C) 2015 Shanghai Century Publishing (Group) Co., Ltd. Shanghai. Reproduced with permission. 
Zhao worked out a structure that connects and provides the transition between sections $\mathrm{B}$ and $\mathrm{B}^{1}$. However, the length is expended by virtue of arpeggios. The musical sentiment becomes more active as the dynamic arises to the " $f f$ ".

Section $\mathrm{B}^{1}$ is also a variation form assembled by one theme and two variated portions. The theme integrates both the material of motive in first beat of phrase $\mathrm{c}$ and the element in transition, which also involves four passages equally divided into four parts in the mm. 141-148 (see Figure 6). The difference occurs in the latter half of the second variation when rhythmic pattern of syncopation is applied to strengthen the dynamic. The second variation breaks the Chinese aesthetic of balance in terms of structure due to its expansion that is approximately twice as long as the sum of theme and first variation. The accompaniment in this part changes from column chords to arpeggios, which becomes the main force underlying the diversity of the chords on the basis of same octave D in the coming expansion. Strengthening the dynamics and widening the registers when changing the timing of notes from eighth notes to fourth notes, the amount of notes from single to chords, the reverse sequence of both the left and right hands at the end of expansion are the means by which music accumulates the power to the climax progressively. This section employed many Western compositional techniques, for instance, a large expansion of second variation is not only opposite to proportionate principle of Chinese aesthetics, but also emphasizes the colorful harmony and surging dynamics.

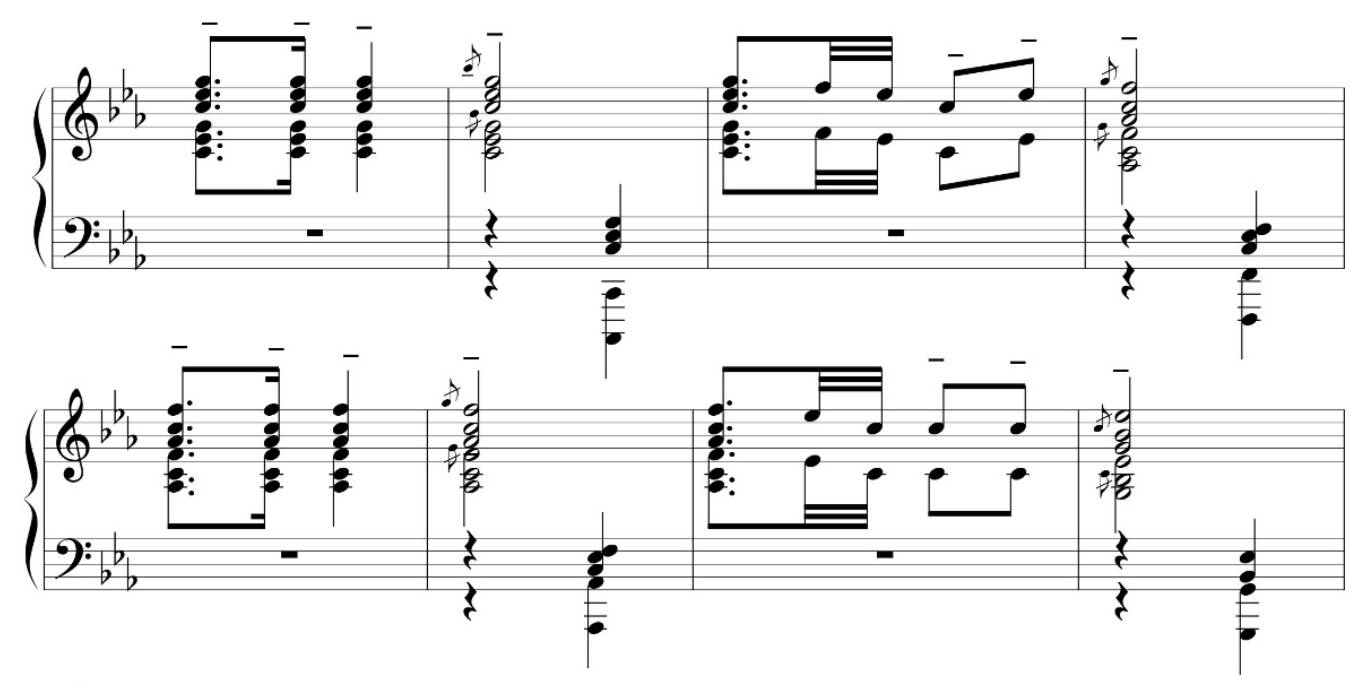

Figure 6. The theme of section B1, mm.141-148. Extract (C) 2015 Shanghai Century Publishing (Group) Co., Ltd. Shanghai. Reproduced with permission.

The third part is an incomplete recapitulation, where reappearance constituted by the partial elements of phrase $a$ and the whole material of phrase $a^{2}$ serves as the climax of the whole composition. However, the rhythm widens from $2 / 4$ to $2 / 2$ in recapitulation and the timing of every note is double extended than before while the accompaniment contexture becomes arpeggio to push the momentum forward and, due to the intention of climax, the melodies of phrase $a^{3}$ and $a^{4}$ are octaves or chords instead of single 
notes in phrases $a$ and $a^{2}$ of first part (see Figure 7). Although the recapitulation reappears as fractional materials of part $\mathrm{A}$, the tonality still follows the rules of classical composition theory that returns to the Ab Gong scale from Ab Zhi scale ( $\mathrm{Ab}$ 徵调) (see Table 4).
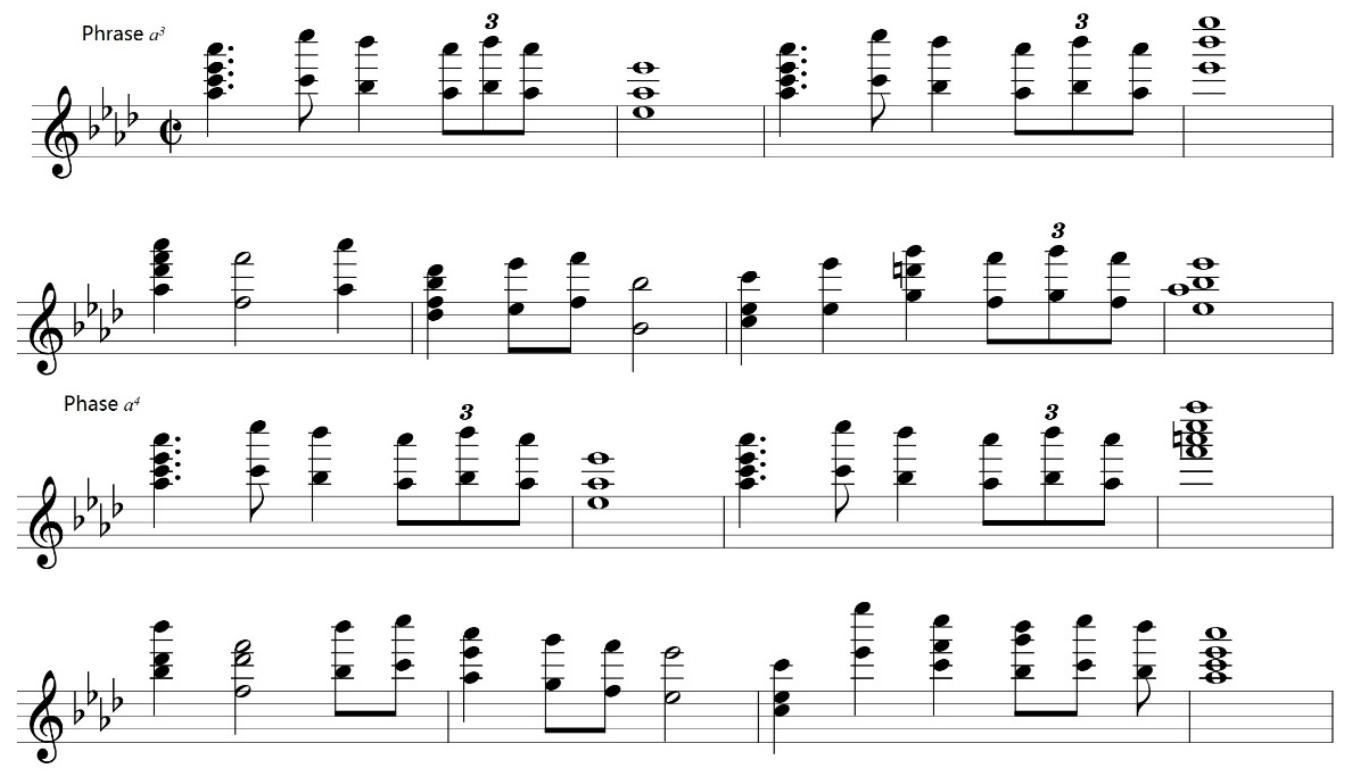

Figure 7. The melodies in recapitulation, mm. 190-205. Extract (C) 2015 Shanghai Century Publishing (Group) Co., Ltd. Shanghai. Reproduced with permission.

Table 4

Structure of Third Part

\begin{tabular}{|c|c|c|}
\hline Part & \multicolumn{2}{|c|}{$\mathbf{A}^{1}$} \\
\hline Section & Theme $\left(A^{3}\right)$ & Variation $\left(A^{4}\right)$ \\
\hline Phrase & $a^{3}$ & $a^{4}$ \\
\hline Measure number & $190-197$ & $198-205$ \\
\hline Key & $\mathrm{Ab} Z h i$ scale & Ab Gong scale \\
\hline
\end{tabular}


Regarding the short recapitulation, Zhao explained that:

The incomplete recapitulation is an important principle for composer... if you transcribe the former score again, [it will be] long-winded and boring, so composer will not want to transcribe. If I have written [the theme] once, why do I need to write it again? [We] must change, once a change is required, incompleteness is a necessity. Chopin, Beethoven, and many others all applied incomplete recapitulation. (translation by authors) (X.S. Zhao, personal interview, November 4, 2017)

The incomplete recapitulation is a typical sample borrowed from the West, and his statement also reflects the influence of Classicism and Romanticism in the end of Cultural Revolution, or even pre-Cultural Revolution ${ }^{2}$.

The coda in Fisherman Song functions as a summary because it contains all elements appearing in the composition such as the form of introduction, melody of theme in part A, motive of transition and connection in part B. However, Zhao did not simply imitate these elements; they reappear in a new way. For example, the materials of introduction

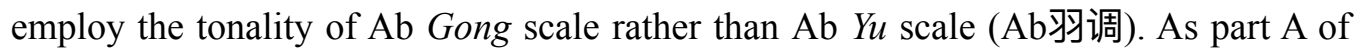
the music reappears, the accompaniment contexture still utilizes the mode of introduction, the music expresses the lingering imagination by arpeggios with right hand and light stuccos with left hand.

\section{Traditional Chinese Scales and Romantic Harmony}

Mittler (1997) pointed that the Chinese music during the Cultural Revolution period show a paradigmatic and pentatonic feature, and even denoted this character as pentatonic romanticism, due to the compositional materials that quote or adapt from folk music in the framework of Western romantic functional harmony. Indeed, Mittler's statement generalized the harmonic phenomenon or, perhaps, the compositional issue of "Chinesenese" at that time. Fisherman Song is one of the examples that have this character Mittler addressed.

Pentatonic scale dominates the tonality of the whole composition, which distinctly shows a Chinese music style. The music begins in $\mathrm{Ab} Y u$ scale and then transfers to $\mathrm{Ab}$ Zhi scale, and then changes as Ab Gong scale in the part A. During the part B, the alternations of tonality corresponding to the requirement for development are beyond the limitation of tonggong xitong (同宫系统, same Gong system) ${ }^{3}$ that is called yigong fandiao (异宫犯调, modulations among different Gong systems) ${ }^{4}$ in the section $\mathrm{B}^{1}$, which are, in sequence, Eb Gong scale, F Yu scale, and Db Shang scale (Db 商调). Although the music in part $\mathrm{A}^{1}$ experiences modulations twice, they return to the original Ab Gong system. The music in coda is in Ab Zhi scale, similar to the introduction and apparently coincides with the principle of Western classical music, in which tonality needs to return to the primary key, yet the difference between them is the final tonality that is identical with introduction rather than part A.

The application of bianyin (变音, additional tone) is the means by which a composer attempts to obtain a colorful tonality and harmony. In pentatonic theory, bianyin 
contains biangong (变宫, B note), qingjue (清角, $F$ note), bianzhi (变徵, F\# note), and run (闰, $B b$ note); A pentatonic scale added with bianyin will generate a hexatonic scale or heptatonic scale. In Chinese traditional music theory, there are three categories of heptatonic tonality, namely yayue scale (雅乐调式), qingyue scale (清乐调式), and yanyue scale (燕乐调式). The yayue scale consists of a pentatonic scale with the bianyin of bianzhi and biangong, the qingyue scale consists of a pentatonic scale with the bianyin of qingjue and biangong, and the yanyue scale consists of a pentatonic scale with the bianyin of qingjue and run. Figure 8 shows the detailed scales of them in the $\mathrm{Ab}$ Gong system to which the music in part $\mathrm{A}^{1}$ belongs.

Scale of yayue

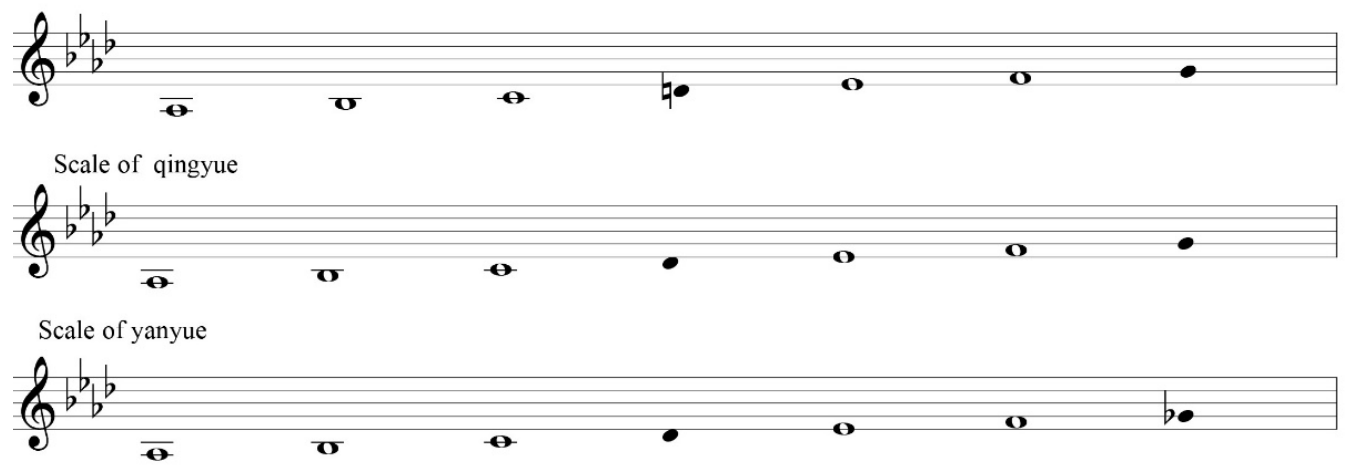

Figure 8 . The scales of yayue, qingyue and yanyue.

Zhao utilized bianyin to create different harmonic effects in Fisherman Song. Such as mm. 8-10 (see Figure 9), Db note that is qingjue in pentatonic scale of Ab Gong system, appears in the melody. Similarly, the bianyin of qingjue transmits to the $\mathrm{Cb}$ note in the following two bars in an abrupt modulation of Gb Shang scale. The adjunction of bianyin in the pentatonic scale that constructs the hexatonic tonality still expresses the colorful pentatonic harmony due to bianyin's dominance in the pentatonic scale or pentatonic frame (Fan, 2010). Therefore, the theme of part A consists of the fundamental pentatonic scale in Ab Gong scale, even though the bianyin of $\mathrm{Db}$ is added in the third and fourth passages. The heptatonic tonality derived from the pentatonic scale emerges in recapitulation $\left(\mathrm{A}^{1}\right)$ as $\mathrm{Db}$ and $\mathrm{G}$ notes are added, with the former representing qingjue and the latter representing biangong. Therefore, the music in part $\mathrm{A}^{1}$ is in qingyue scale due to the bianyin of qingjue and biangong (see Figure 10). 


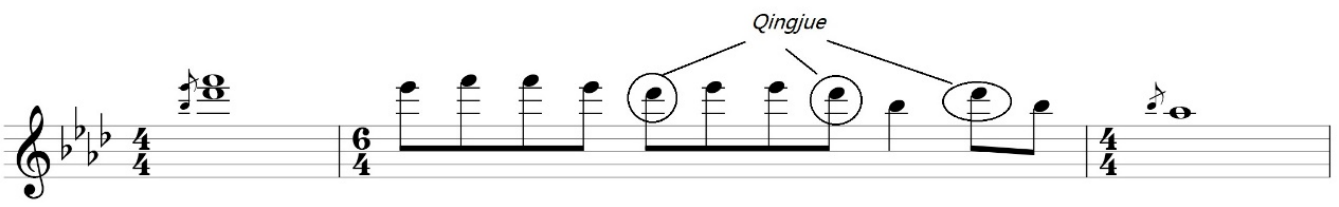

Figure 9. Qingjue in pentatonic scale of Ab Gong system, mm. 8-10. Extract (C) 2015 Shanghai Century Publishing (Group) Co., Ltd. Shanghai. Reproduced with permission.

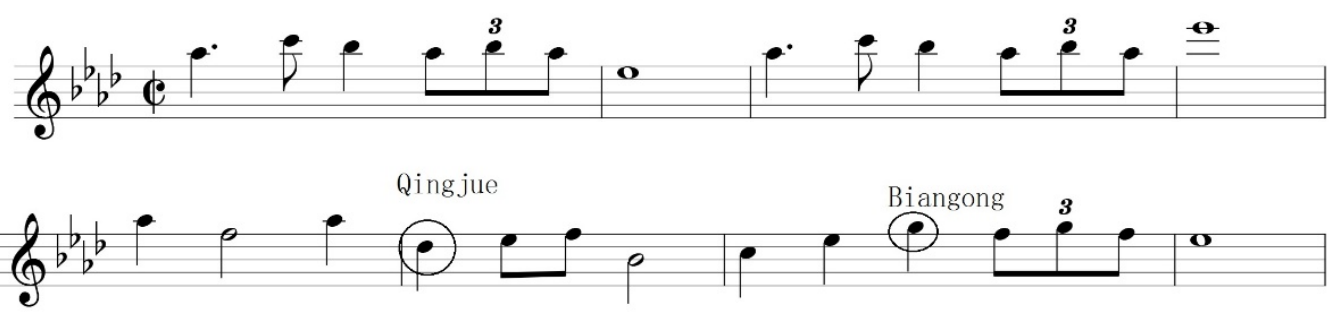

Figure 10. The bianyin of qingjue and biangong in part $\mathrm{A}^{1}$, mm.190-197. Extract (C) 2015 Shanghai Century Publishing (Group) Co., Ltd. Shanghai. Reproduced with permission.

Pentatonic chords are crucial to construct the pentatonic harmonic style in Fisherman Song. In general, there are four categories of harmony reflected in the different formal chords of this composition: linear harmony, colorful harmony, functional harmony, and compound harmony. The following section further explains these categories in details.

Sparks of modern harmony in the polychord at mm. 189 Fisherman Song brings in a touch of modernism that presents a hint of dissonant and intensive calling in a romantic soundscape. According to Vincent Persichetti (1961), polychord is defined as two chords in different harmonic areas that are simultaneously combined with each other. The purpose of polychord in Fisherman Song is to strengthen the dissonant tension in anticipating climax (see Figure 11). In addition, the polychord herein also represent an anticipated chord of the forthcoming key in $\mathrm{Ab}$. As seen in Figure 11, the chord consists of $\mathrm{F}, \mathrm{Bb}, \mathrm{Db}$, and $\mathrm{F}$ under the $\mathrm{F} \mathrm{Yu}$ scale while the bottom chord displays a tonality of $\mathrm{Eb} Z h i$ scale. Both are dominated in $\mathrm{Ab}$ Gong system to prepare the appearance of $\mathrm{Ab}$ Gong scale in later context. 

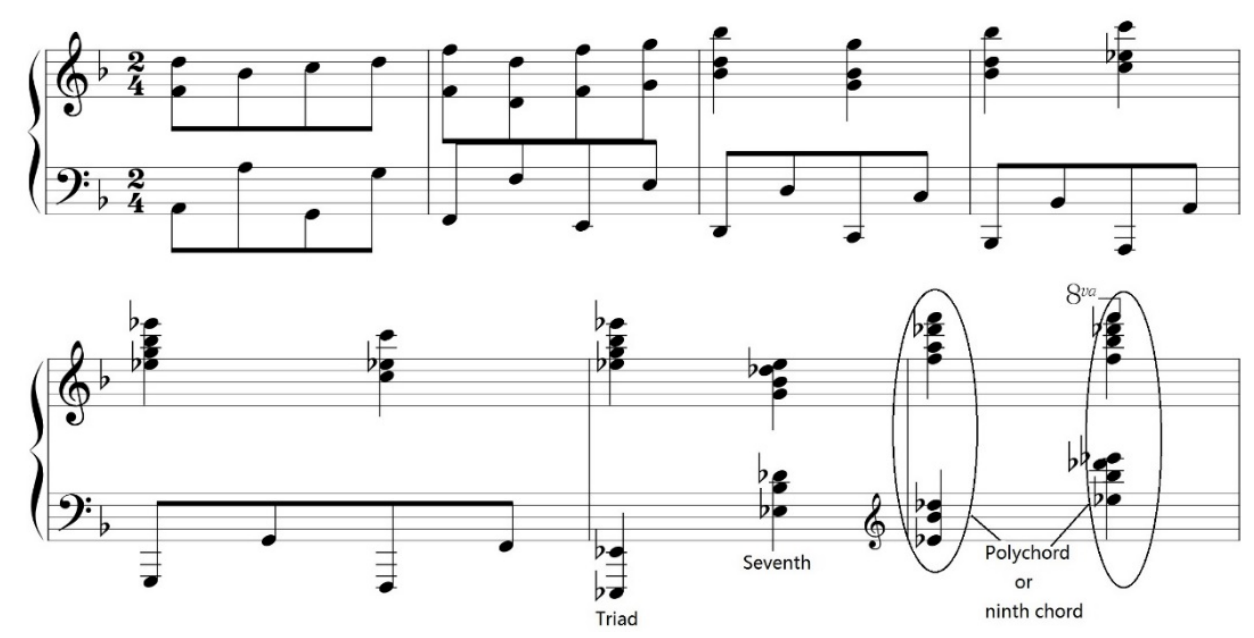

Figure 11. The polychord or ninth chord, mm. 183-189. Extract (C) 2015 Shanghai Century Publishing (Group) Co., Ltd. Shanghai. Reproduced with permission.

In viewing the same chord from major and minor mode from a Western perspective, the polychord will then be regarded as a ninth chord with the dominant function, and an apex of tension and color gradations from triads to ninth through seventh, to obtain a chromatic resolution in the recapitulation and the climax of whole composition.

In $\mathrm{mm}$. 165-177, the colorful harmony is displayed by the diversity of chords that are constructed on the same roots (D note) and derived arpeggios, which are respectively major triad, minor triad, diminished seventh chord, dominant seventh chord in third inversion, and so forth (see Figure 12). This type of composing technique breaks through the limitation of tonality and emphasizes on the color of harmonies rather than function, just as the findings of Hua Cuikang (1989) who said that colorful harmony corresponds the sequence of attribute although it is not restricted by tonality. Meanwhile, with the harmonic progression laying on the attributes of chords, the music also reflects a gradual increase of tension that also facilitates increasing power.

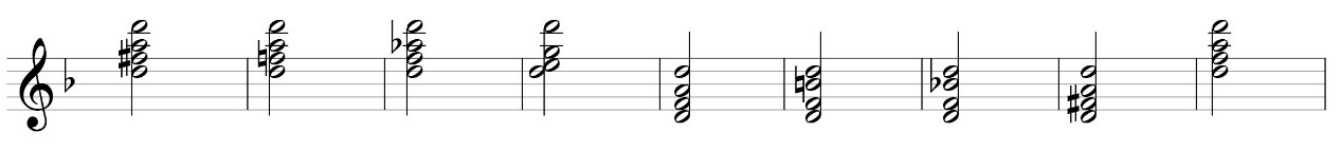

Figure 12. Chords constructed on the same roots to pursuit colorful harmony.

The structure of the fourth and fifth intervals is one of the methods to constantly express linear harmony in pentatonic harmony (Fan, 2002). In Fisherman Song, the applications of the fourth and fifth intervals are widespread such as melody in $\mathrm{mm}$. 6-7 (see Figure 13), theme in mm.23-24 (see Figure 14), among others. 


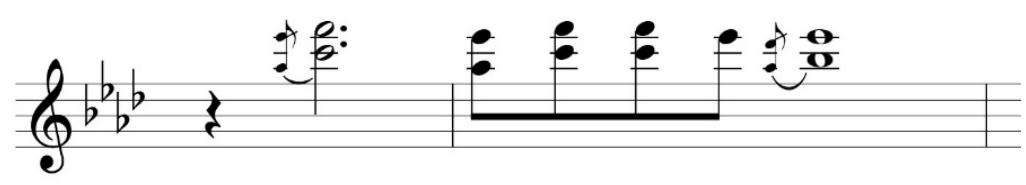

Figure 13. The melody consists of fourth and fifth intervals, mm.6-7. Extract (C) 2015 Shanghai Century Publishing (Group) Co., Ltd. Shanghai. Reproduced with permission.

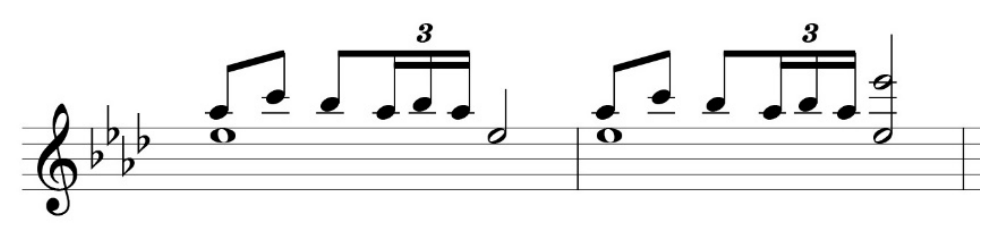

Figure 14. The melody consists of fourth and fifth intervals, mm.23-24. Extract (C) 2015 Shanghai Century Publishing (Group) Co., Ltd. Shanghai. Reproduced by permission.

The application of quartal harmony built in fourths in contemporary compositions reflecting in works by Debussy, Schoenberg, Stravinsky, Webern, and Hindemith as well as many other modern composers (Persichetti, 1961; Schoenberg, 1911). As such, it is as commonly used as tertian chords harmony in the Classical and Romantic periods. In mm. 22, the quartal chord appears as the portion of melody (see Figure 15).

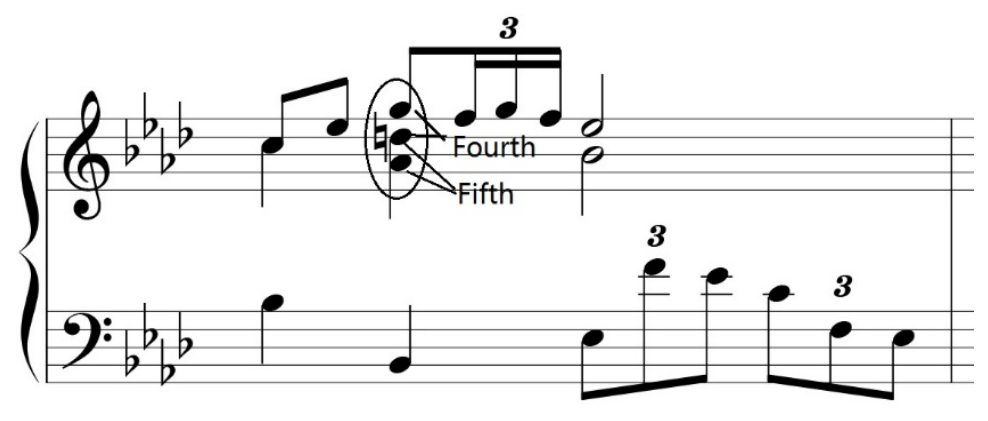

Figure 15. The quartal chord, mm.22. Extract (C) 2015 Shanghai Century Publishing (Group) Co., Ltd. Shanghai. Reproduced with permission.

Another type of chord is the superimposition of fourths and fifths, which is a traditional technique of pentatonic harmony to create the sound of space and elegance (Fan, 2002). Besides that, this chord is a feature of tonality in Debussy's works and simultaneously it is called pipa ${ }^{5}$ chord, due to its similar intervals with pitches of empty string on pipa (Yu, 2014). The musical materials in the third phrase of section $\mathrm{B}^{1}$ is the sample of this harmony (see Figure 16), by which music changes a cantabile melody from the past dynamic motive. Moreover, the color of harmony is higher than 
before due to the added-notes $\mathrm{CH}$ and $\mathrm{F}$ filling out the chords to establish the augmented, diminished and perfect fourths in the bottom and diminished, augmented and perfect fifths at the above respectively.

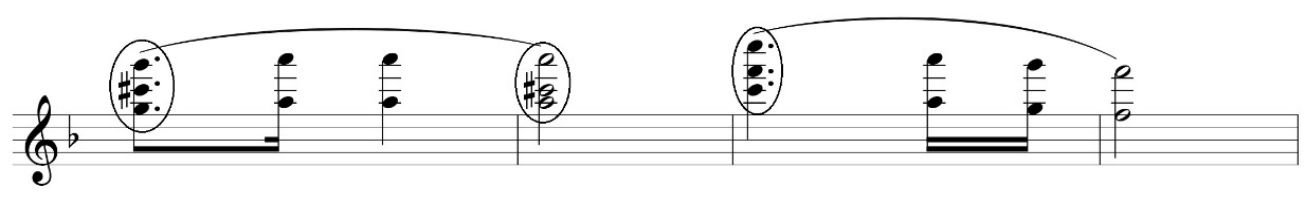

Figure 16. The superimpositions of fourths and fifths, mm.157-160. Extract (C) 2015 Shanghai Century Publishing (Group) Co., Ltd. Shanghai. Reproduced with permission.

\section{Chinese Folk Music Reflected in Tempo}

The tempo of Fisherman Song serves for the expression of mood. Zhao ingeniously employed three types of time-signatures $(4 / 4,5 / 4,6 / 4)$ with arpeggios of thirty-second notes and sixteenth notes in the introduction to reflect the rough sea. In addition, conforming to the convention of Chinese folk music, the tempo is relatively free with minimal marking such as ritardando, Precipitano, meno mosso, and allargando.

As the music comes into part A, the tempo becomes steady and strict, even though the accompanying context returns to the pattern of arpeggios from the second variation onwards. In the third variation, the two marks of ritardando symbolizes the end of part $\mathrm{A}^{1}$. A distinctive change of tempo employed in part $\mathrm{B}$ describes a scene of fishing that is the exertion of a small ship facing huge waves. The time-signature changes from $4 / 4$ to $2 / 4$ to establish a powerful and staunch musical career due to imitation of lawang haozi melody. While the tempo suddenly increases in the first variation, the rhythm pattern becomes triplet in the second variation. In section $\mathrm{B}^{1}$, the tempo is slower and sustains until mm. 189. The music entering into third part implies the happiness of harvest and subjugation of difficulties; the tempo, therefore, becomes wider under the effect of $2 / 2$. In the coda, the tempo is similar to the introduction due to the symmetry principle corresponding the structure and recording of Zhao's performance.

\section{Melody}

Diversity of melodic patterns emerge in Fisherman Song reflects the complex life living in the sea. For example, hidden melodies within arpeggios, pentatonic melodies, melodies in the mode of lawang haozi, passionate melodies with octaves that is broadening in character.

At the beginning of Fisherman Song, melodies exist as the line of notes that are marked by "." in the arpeggios (see Figure 1). The melody shape bears similarity with works such as Chopin's Etude Op. 25 No. 1, Prelude from Pour Le Piano by Debussy, or even in piano works that reflects water such as Reflets dans l'eau by Debussy and Jeux d'eau by Ravel (Park, 2012). However, the difference with them is the melodies herein outlining a pentatonic line of "F-Eb-C-Bb- Ab- F- C- F" in $A b$ Gong scale.

Pentatonic melodies is based upon the pentatonic harmony, so Zhao utilizes limited 
notes to depict a theme divided into three passages. In mm. 17-22, the melody establishes on the combination of five notes in Ab Gong scale at the first passage while the second passage comes in with the reverse third at a higher octave apart and the rhythmic pattern of eighth note plus sixteenth-note triplet. In the third passage, the melody develops in a new mode, which returns to the original mode in the last half passage (see Figure 17).

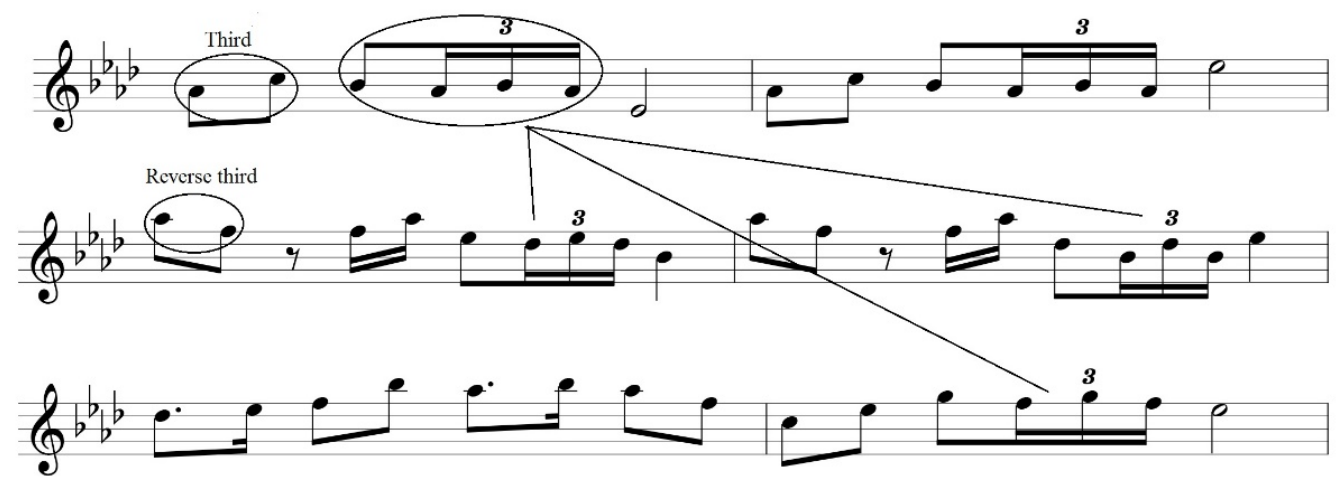

Figure 17. The development of pentatonic melodies, mm.17-22. Extract (C) 2015 Shanghai Century Publishing (Group) Co., Ltd. Shanghai. Reproduced with permission.

Due to Zhao's personal experience regarding fishermen's work, creative melodies imitating lawang haozi reflect the interaction between the lead singer and chorus that forms a call and respond. Yet, the chorus lyrics are mostly auxiliary words in a rhythmic mode, such as "hey" and "yo", to replicate fishermen who strenuously pull the fishing net together while the auxiliary words sung by the lead singer at the beginning symbolizes the action of calling all fishermen to collectively pull the fishing net. Compared to the work song, the form of lawang haozi in part B distinctly reappear in the scene of pulling the fishing net onto the vessel. The second notes with ornament in mm. 51-52 represent the lead singer's call for the collective fishermen while the fourth notes with ornaments in the second and fourth voices describe the echoes of the collective fishermen: both of them constitute a call and respond. In the following music, four two-bar echoes (mm. 57-58, mm. 63-64, mm. 69-70, and mm. 75-76) as the padding syllable of work song that is inserted in the four phrases of theme. This shows that the melodies of the lead singer is a melodic exemplification of lawang haozi (see Figure 18). 


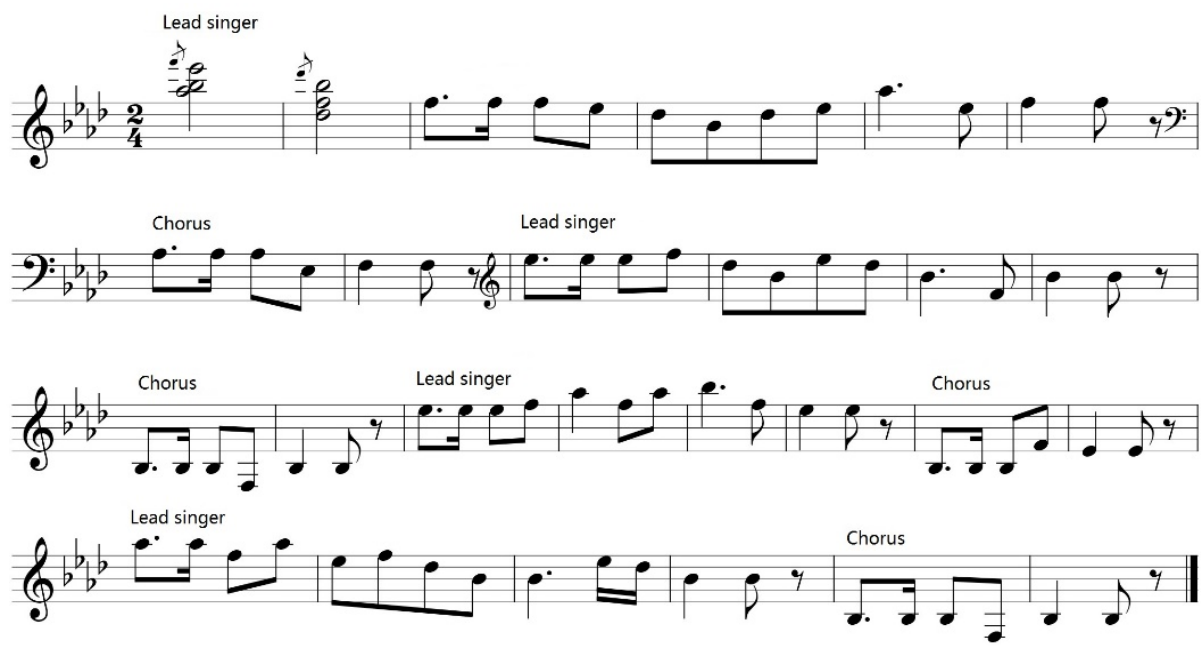

Figure 18. Imitation of Lawang haozi, mm.51-76. Extract (C) 2015 Shanghai Century Publishing (Group) Co., Ltd. Shanghai. Reproduced by permission.

As the basic elements of Chinese work songs, padding syllable and lining cavity applied in Fisherman Song depict a painting of fishermen who are pulling the net together and are pleased with their harvest. However, the presentation of work song about labor employment via the piano, a Western musical instrument, is a challenge for performers. Therefore, an understanding of the relationship between the lead singer and lining chorus is crucial when recreating the lively scenes on piano. According to the explanation of the work song of Pulling Fishing Net, when the lead singer sings one phrase while the chorus sing or rap the padding syllable such as "hey", and "yo" simultaneously, the dynamic ought to be played in difference so that the part of lining cavity will be louder and more confirmed than the lead singer one and the timbre will be close to the echo; this makes the leading cavity be a little bright while lining one is inclined to darkness. In addition, due to the function of padding syllable and lining cavity being an agglomerate of power from the fishermen by virtue of intense rhythms, the effect on short and plain sound is the pursuit to interpret the portion of padding syllable and lining cavity. Hence, the straightforward touching without paddling is dispensable.

In terms of recapitulation where the climax appears, the reprise of the melodies were treated with octaves in treble region in longer timing. The added time in note value builds distance between melody and accompaniment of arpeggios, as well as the musical enthusiasm ignited by the momentum that the octave impacts upon. Meanwhile, the different display between melodies represented in part $\mathrm{A}$ and $\mathrm{A}^{1}$ precludes the mundane repetition and reflects the principle ternary form required.

Upon viewing the complete text of Fisherman Song, the compositional technique of variation occupies an important position while the performance of variations is more complex. Due to the relationship that variations are derived from theme, it is necessary for performers to identify the shadow of theme from variations, which is the cardinal line to connect the theme and variations in order to maintain unity in musical thinking. 
For instance, there are two variations in section B, which are variated by the change of rhythmic pattern, tones, tonality, and many more. Assuming the omission of all notes in chords and intervals except for the upper notes, the melodies of theme will be shaped as the mode of single notes, correspondingly, the compared contour will be shown as the only melodic notes that are reserved in two variations (see Figure 19). Then, it can be further hypothesizes that combining the same notes and transforms to equivalent value notes, the resultant of which reveals that the elements of variations are from the motives of theme, with an amplified rhythmic pattern (see Figure 20). According to X.S. Zhao's live performances (personal interview, November 4, 2017), the first note in the group of same notes were emphasized in order to depict the melodic line. Moreover, the melody transfers to the second note of triplet in the second variation; in other words, melodic notes are placed at the upbeats. Therefore, the stability of rhythmic pattern cannot be ignored as the octaves are highlighted as the melodies.
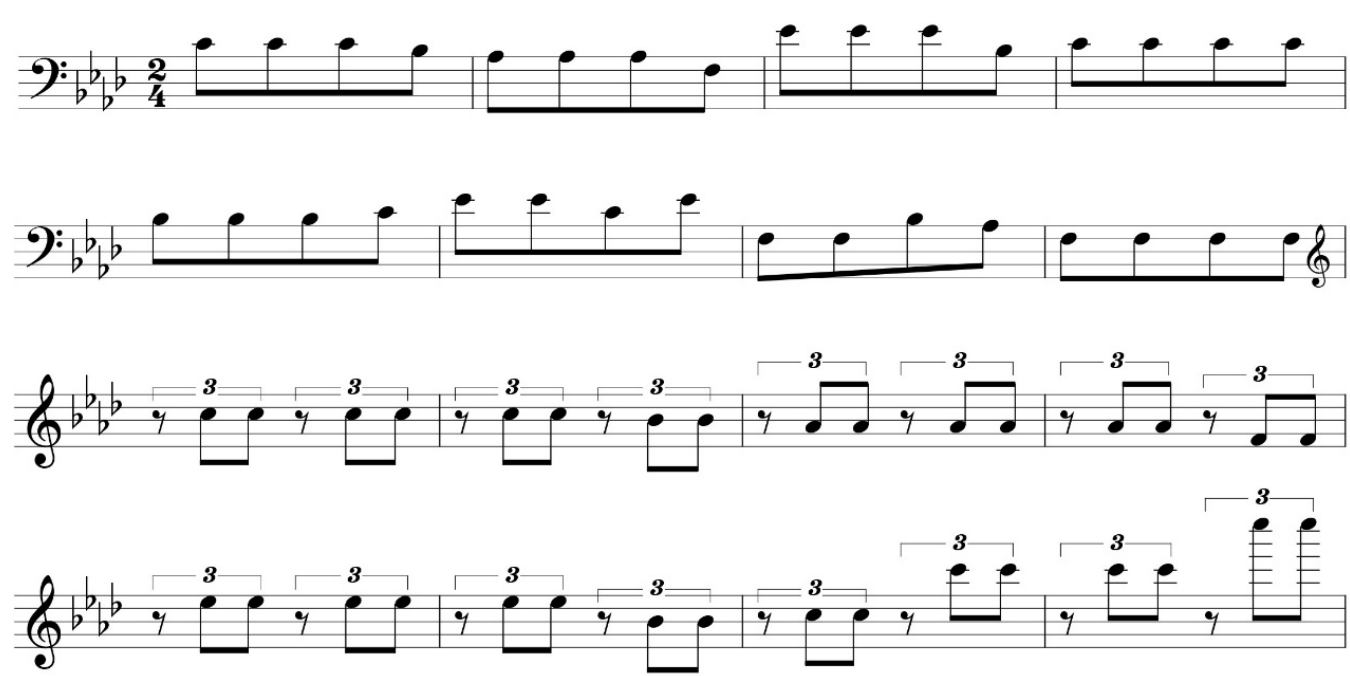

Figure 19. Melodic notes in two variations, melodic notes in first variation, mm.77-84; melodic notes in second variation, mm.93-100. Extract (C) 2015 Shanghai Century Publishing (Group) Co., Ltd. Shanghai. Reproduced with permission.
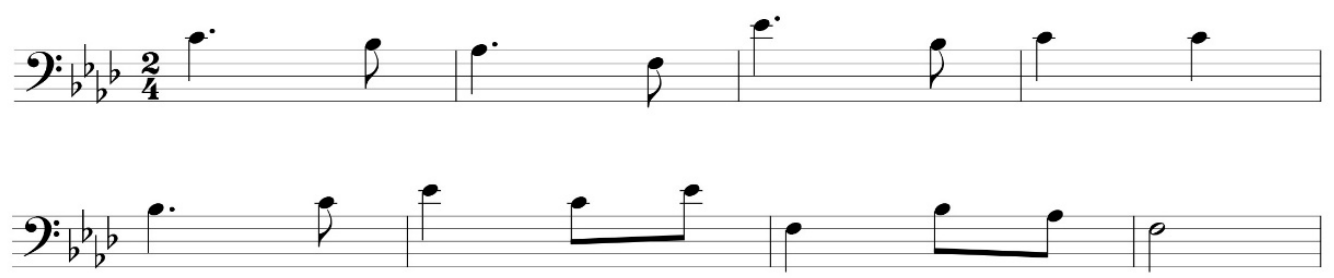

Figure 20. Equivalent value notes of melodic notes in two variations, adapted by authors. 


\section{Discussion and Conclusion}

Although Zhao was renown by virtue of his piano solo Tai Chi in 1987, his success was paved by many piano composition practices, such as Fisherman Song (1975), Ballade in Db Major (19766), Ballade in D Gong Scale (1976), and The Hegemon King Takes off his Armor (1981). Probably, these compositions may not as reputable as Tai Chi, but reflected Zhao's intention for "Chineseness" and China's history as a core identity of these piano music.

As Mittler (2003) described, the music, especially model works, served the politics during this period between 1966 and 1976. Fisherman Song was composed in the end of Cultural Revolution, more or less responds the requirement that propagated the proletariat at that time. In terms of this, Zhao said frankly, "every composition is influenced by its era environment" (X.S. Zhao, personal interview, November 4, 2017). Maybe that is a reason that Zhao submit this composition to be published while others composed in the same time were not submitted. Nevertheless, Fisherman Song shows much more romanticism than other coetaneous compositions, such as model works or adaptions of traditional music. This becomes a clean stream to arouse the chaos music of that time by virtue of its neo-romantic character such as the composer's pursuit of harmonic color, expression of feelings, sentiments, or even imaginations.

With the programmatic character, the piano music in Cultural Revolution focuses on the description and depiction (Liang, 1996). Zhao's Fisherman Song can be viewed as the typical sample in this period, by possessing headline and depicting fisherman's life. However, there are some issues of compositions reflected in this period too.

First of all, the synthesis between the Western and Chinese musical theories may be simple and even a little far-fetched. In Fisherman Song, although the combinations of Western and Chinese elements such as forms and harmonies are fused, that is only a fusion of common points both of them. Taking the bi-structure as an example, the compound ternary form seems similar with yanzhanti, but the segments in different forms play different roles. The section of introduction in compound ternary form is usually short and general while it is placed in yanzhanti as part A, the function is changed, which become an independent part with definite significance. To be honest, due to the one-part form consists of paralleled four phrases and completed musical description, the part of introduction in Fisherman Song is likely to be the first part of yanzhanti, rather than an introductory part of Western music. Thus, the synthesis of the Western and Chinese concepts seems unsmooth; this is a usual phenomenon in Chinese style compositions during 1970s. Therefore, the advanced mergence asks for a relatively innovated compositional theory that is neither a superficial combination of the Western and Chinese theories nor a closed outdated ideal. Fortunately, the requirement of new theories became true in 1980s and 1990s as more and more ingenious theories emerged, such as Zhao's Tai Chi Composition System, Peng Zhimin's Sequence Theory, Fang Xiaomin's Five Phases Compositional Theory, Chung Yiu Kwong's I Ching Compositional System, and Wu Shaoxiong's Ten Celestial Stems Compositional Theory.

Secondly, melodic writing is important in reflecting the identity of Chinese instrumental music due to the heterophonic texture. The import of the Western piano to 
China put a quest to aesthetic consideration of the binary between the West and East. Melodies accompanied by arpeggios or combined in polyphony was witnessed as core characteristic in contemporary piano compositions, such as He Luting's Buffalo's Flute, $\mathrm{Ni}$ Hongjin's Suite of Zhuang, Chu Wanghua's Liuyang River, and even Yin Chengzong's Red Lantern in the period of Cultural Revolution. The same applies to Fisherman Song and simultaneously exposes a defect that Zhao's compositional vision was limited due to the few contacts with Western music and nearly zerocommunication with abroad during Cultural Revolution. Of course, it was not only Zhao's personal problem, it was an universal problem of Chinese piano music, yet this situation was changed as ended and many composers, such as Zhou Long, Tan Dun, Chen Yi, and Zhao Xiaosheng, went to the United States and European countries in 1980s (Kouwenhoven, 1990).

Furthermore, tonal composition was the mainstream during Cultural Revolution, which is also the feature of tonality in Fisherman Song. Indeed, atonal piano works has appeared as early as 1947 in the piece From Far Away by Sang Tong (Kouwenhoven, 1990), but it became weak in Cultural Revolution and was replaced by traditional pentatonic scale. The wave of adapting folk and model opera music is the efficient method to popularize the application of pentatonic because most folk music continue the tradition of pentatonic tonality. In addition, the tonality of Fisherman Song makes the scene of Impressionistic or modernist features, such as the application of the fourth and fifth superimposed chords, polychord, and quartal harmony, even though they are fragmental.

In Fisherman Song, the applications of tonality, harmony, and melody present the mature understanding to the Western Romanticism, which is differentiated with Zhao's later piano compositions that were composed during his abroad study and return from the United States, such as Tai Chi. Fisherman Song marked Zhao's earlier composition as well as his hardship surviving in the sea as a fishing labor. Compared to Zhao's later compositions, this composition seems a little naive and lack of obvious individuality, but it has its pianistic success in a sonic-portrayal of fishermen's labor and hardship during the Cultural Revolution period. The chaos of crashing waves in the music of Fisherman Song perhaps, in some ways, reflects the composer's inter-personal entanglement of his Western musically trained background and his quest of neoromanticism in a Chinese musical and cultural endeavor.

\section{Endnotes}

${ }^{1}$ Haozi means work song and lawang is translated as "pulling fishing net". It is a work song that was sung during fishermen's work. The music and movement is synchronous that enables a leader and followers to move as a team when they are pulling the heavy fishing net.

2 Culture Revolution seems a barrier of the Western music theory or thoughts, the Chinese music conceptions are ceased. Therefore, it is possible that musicians' knowledge is limited on the level of pre Culture Revolution. 
${ }^{3}$ In a pentatonic tonality, there are five scales in a Gongxitong (宫系统, Gong System). The key signatures in introduction and part $\mathrm{A}$, for example, are $\mathrm{Bb}, \mathrm{Eb}, \mathrm{Ab}$ and $\mathrm{Db}$, the Gong system will be Ab Gong system, and which embodies Ab Gong scale (Ab宫调), $\mathrm{Ab}$ Shang scale (Ab商调), $\mathrm{Ab}$ Jue scale (Ab角调), $\mathrm{Ab} Z h i$ scale (Ab 徵调) and $\mathrm{Ab} Y u$ scale (Ab羽调).

${ }^{4}$ As Fan Zuyin's (2010) explanation, there are two categories of modulations that are tonggong fandiao (同宫犯调) and yigong fandiao (异宫犯调) in traditional musical theory. Tonggong fandaio means alternative tonality occurs in the same Gong system, while yigong fandiao indicates modulations among the different Gong system.

5 Pipa (琵琶), or Chinese lute, is a Chinese traditional instrument.

${ }^{6}$ Ballade in Db Major was marked 1977 in publications, yet Zhao disclosed that it was actually composed in 1976 during the interview, and he hid that intentionally. 


\section{Acknowledgement}

This research is supported by UMRG grant RP038A-17HNE.

\section{References}

Fan, L. (2015). Lun Qichengzhuanhe Qushi Jiegou zai Minge Xiaodiao zhong de Shenmei Yiyi [论起承转合曲式结构在民歌小调中的审美意义，The Discussion of Aesthetics of Qi, Cheng, Zhuan and He in Folk Song] Song of the Yellow River (Vol. 2015, pp. 79-80).

Fan, Z. (2002). Siwudu Jeigou yu Erdu Jiegou de Hesheng Fangfa [四五度结构与二 度结构的和声方法, The Harmonic Methodology for the Structure of fourth, fifth and seond intervals]. Huangzhong-Journal of Wuhan Music Conservatory, 2002(2), 3-14.

(2010). Wushengdiaoshi Hesheng Yanjiu Santi [五声调式和声研究三题, Three Issues of Pentatonic Harmony study]. Paper presented at the National Seminar about Harmonic and Polyphonic Pedogogy, Beijing.

Hua, C. (1989). Hexian de Secai Dengji yu Hesheng de Secai Xulie [和弦的色彩等级 与和声的色彩序列, The Colorful Level of Chords and the Colorful Sequence of Harmonies]. Journal of Nanjing Arts Institute (Music \& Performance), $1989(3), 2-10$.

Huang, Q. (2010). Lun Qichengzhuanhe [论起承转合, Discussion of qi, cheng, zhuan and he]. Jinyang Xuekan, 2010(3), 124-129.

Jiang, M. (1999). Hanzu Minge Gailun [汉族民歌概论， Introduction to Han Folksong]. Shanghai Music Press: Shanghai.

Kang, L. (2009). The Development of Chinese Piano Music. Asian Culture and History, 1(2), 16.

Kong, W. (2009). Qinrenheyi, Yixinshenyou - Zhao Xiaosheng Gangqin Yinyue Yanjiu [天人合一，依心神游一一赵晓生钢琴音乐研究, Syncretism of Piano and Human, Wander of Following Heart - a Research on Zhao Xiaosheng's piano music]. (Master's thesis). Shandong Normal University, Shandong, China.

Kouwenhoven, F. (1990). Mainland China's New Music (1): Out of the Desert. Chime Journal, Autumn(2), 58-93. 
Li, T. (2014). Zhao Xiaosheng Gangqin Zuopin de Chuangzuo Tezheng Fenxi [赵晓生 钢琴作品的创作特征分析, The Analysis of Piano Composition Feature by Zhao Xiaosheng]. Stage, 2014(12), 114-115.

Liang, M. (1996). Wenhua Dageming Shiqi de Yinyue [“文化大革命”时期的音乐, The Music in Cultural Revolution] Jiao Xiang -Journal of Xi'an Conservatory of Music (Vol. 1996, pp. 17-21).

Liu, X. (1978). Yigai (Jingyi Gai) [艺概(经义概), Generality of Arts (Generality of Jingyi)]. Shanghai: Shanghai Ancient Books Publishing House.

Mittler, B. (1997). Dangerous tunes: The politics of Chinese music in Hong Kong, Taiwan, and the People's Republic of China since 1949. Wiesbaden: Harrassowitz.

(2003). Cultural Revolution model works and the politics of modernization in China: An analysis of "Taking Tiger Mountain by Strategy". The World of Music, 45(2), 53-81. Pang, L., Clark, P., \& Tsai, T. H. (2016). Listening to China's Cultural Revolution: Music, politics, and cultural continuities. Hampshire: Palgrave MacMillan.

Park, S. H. (2012). Elements of impressionism evoked in Debussy and Ravel's Reflects dans I' eau and Jeuxd'eau: The theme of water. (Doctoral dissertation), University of Washington, Seattle.

Persichetti, V. (1961). Twentieth century harmony. London: Faber and Faber Limited.

Robinson, J. (1968). The Cultural Revolution in China. International Affairs (Royal Institute of International Affairs 1944-), 44(2), 214-227.

Schoenberg, A. (1911). Theory of harmony (R. Carter, Trans.). London: Faber and Faber Limited.

Yu, Q. (2014). Impressionistic music features in Chinese piano works. Cross-Cultural Communication, 10(6), 195-205. 